\title{
RETRACTED ARTICLE: Feature selection for diagnose coronavirus (COVID-19) disease by neural network and Caledonian crow learning algorithm
}

\author{
Mokhalad abdulameer kadhim alsaeedi ${ }^{1} \cdot$ Sefer Kurnaz ${ }^{1}$
}

Received: 15 September 2021 / Accepted: 9 October 2021 / Published online: 7 February 2022

(c) King Abdulaziz City for Science and Technology 2022

The Editor-in-Chief and the publisher have retracted this article. The article was submitted to be part of a guestedited issue. An investigation by the publisher found a number of articles, including this one, with a number of concerns, including but not limited to compromised editorial handling and peer review process, inappropriate or irrelevant references or not being in scope of the journal or guest-edited issue. Based on the investigation's findings the Editor-inChief therefore no longer has confidence in the results and conclusions of this article. Author Mokhalad Abdulameer Kadhim Alsaeedi disagrees with the retraction. Author Sefer Kurnazdisagreeshas not responded to correspondence regarding this retraction.
The online version of this article contains the full text of the retracted article as Supplementary Information.

Supplementary Information The online version contains supplementary material available at https://doi.org/10.1007/s13204-021-02159-x.

Publisher's Note Springer Nature remains neutral with regard to jurisdictional claims in published maps and institutional affiliations.

Springer Nature or its licensor (e.g. a society or other partner) holds exclusive rights to this article under a publishing agreement with the author(s) or other rightsholder(s); author self-archiving of the accepted manuscript version of this article is solely governed by the terms of such publishing agreement and applicable law.
Mokhalad abdulameer kadhim alsaeedi

mokhalad.alseedi@ogr.altinbas.edu.tr

Sefer Kurnaz

sefer.kurnaz@altinbas.edu.tr

1 Department of Electrical Computer Engineering, Altinbas University, Istanbul, Turkey 